\title{
Cytotoxicity Profile of Calix[4]pyrrole Derivatives on HeLa and MCF-7 Human Cancer Cell Lines via In vitro Study and Molecular Modelling
}

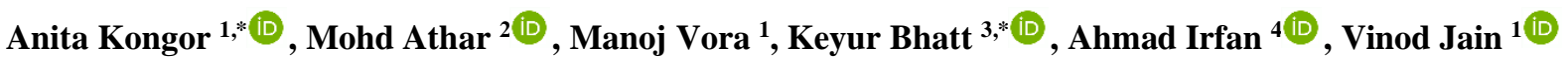 \\ 1 Department of Chemistry, School of Sciences, Gujarat University, Navrangpura, Ahmedabad - 380009. India; \\ anitakongor_chem@outlook.com (A.K.); manojvora.2410@gmail.com (M.V.); \\ 2 Department of Chemistry, Indian Institute of Technology Madras, Chennai-600036; mathar98@gmail.com (M.A.); \\ 3 Mehsana Urban Institute of Science, Department of Chemistry, Ganpat University, Kherva, Gujarat, 384012, India; \\ drkdbhatt@outlook.com (K.B.); \\ 4 Department of Chemistry, College of Science, King Khalid University, Abha 61413, P.O. Box 9004, Saudi Arabia; \\ irfanahmad@kku.edu.sa (A.I.); \\ * Correspondence: anitakongor_chem@outlook.com (A.K.); drkdbhatt@outlook.com (K.B.);
}

Scopus Author ID 56709598400

Received: 14.09.2021; Revised: date; Accepted: date; Published: date

\begin{abstract}
Amongst significant macromolecules, the cytotoxic activity of calixarene analogs is significant due to their unique biomedical properties. Recently, calix[4]pyrrole have shown remarkable efficacy and have extended new dimensions towards different biomedical and therapeutic applications. Herein, meso-tetra (methyl) meso-tetra (3-methoxy 4-hydroxy phenyl) calix[4]pyrrole (HMCP) have been studied for their remarkable cytotoxic activity against HeLa and human breast adenocarcinoma (MCF-7) cancer cell lines in comparison to its hydrazide derivative, meso-tetra (methyl) meso-tetra (3methoxy 4-hydroxy phenoxy acetatohydrazide) calix[4]pyrrole (MCPTH). Cytotoxicity assays were studied at varying concentrations where HMCP molecule was very active against cancer cell lines with G150 values less than 10 . The cell viability has been examined by SRB assay. The anti-cancerous activity results of HMCP can be potentially extended with applications in cancer therapies. Furthermore, the structure and anti-cancer activity relationship has been supported by molecular docking study of the active compounds against quinone reductase-2 (PDB ID 4ZVM) protein.
\end{abstract}

Keywords: cytotoxicity; calix[4]pyrrole; anti-cancer; quinone reductase-2; molecular docking.

(C) 2021 by the authors. This article is an open-access article distributed under the terms and conditions of the Creative Commons Attribution (CC BY) license (https://creativecommons.org/licenses/by/4.0/).

\section{Introduction}

Calixarene systems are a unique class of supramolecules that can be functionalized at both upper and lower rims. Calixarenes are third-generation supramolecules that can be easily functionalized and thus, possess the potential to mark a milestone in the development of novel functionalized compounds [1]. Thus, research on calixarene-based derivatives is gaining much interest because of their larger cavity, which can adopt the most suitable conformation to encapsulate/bind with any biomolecule and induce a coordination complex through different non-covalent interactions. This can be achieved by specifically tailoring the number and type of interactions among host and guest [2]. Modified calixarenes are interesting to study applications such as sensing, catalysis, device making, and biological applications [3-6]. The modification of calixarenes is very significant to achieve specific application which distinguishes it from other heterocyclic molecules. Their synthetic availability, low toxicity, 
and the presence of reactive sides are characteristics that position them in a relevant place within supramolecular chemistry $[6,76]$.

Calix[4]pyrroles are heterocyclic analogs of calix possessing four pyrrole units. With the evolution of supramolecular chemistry, calix[4]pyrrole have emerged as very versatile macromolecules with a wide range of applications, spanning from ion recognition to being lead-compounds for the development of new biomedical applications [8-10]. Antibacterial and cytotoxic effects against cancer cell lines have been reported for different calix[4]pyrrole compounds [11,12]. Calix[4]pyrroles have recently been studied by Geretto et al. for anticancer activity against A549 cancer cells. The research team has reported using a calixpyrrole derivative for potential biomedical applications as a drug-delivery system for the first time [13]. Zhou et al. have explored and reviewed new targeting supramolecular chemotherapy combining diagnostic and therapeutic functions. Through which an intriguing notion is reminisced to motivate new chemists towards advanced supramolecular chemotherapy based on host-guest recognition and promote translational clinical application [14]. Calix[4]pyrrole unit has been studied as metal transporter to the DNA bases by Cafeo et al. the phosphate anion-binding properties. The in vitro tests of the new trans-calixpyrrole-Pt(II) complex on different cancer cell lines indicated significant cytotoxic activity that is unquestionably derived from the coexistence of both the trans-Pt(II) fragment and the calix[4]pyrrole unit [15]. In the same context, the chemical modifications grounded on our previous studies led us to identify bio-medicinal potentiality of calix[4]pyrrole capped nanoparticles such as DNA interactions [16], antioxidant [17], and antibacterial studies [10]. Intriguingly, the present study aimed to elaborate that parent calix[4]pyrrole compound also possesses bio-medicinal potentiality compared to their functionalized nanoparticles. The solubility or intrinsic molecular property of the calix[4]pyrrole compound may be related to such a research arena. Therefore, presently to understand more deeply the anti-cancer activity, computational data were substantially studied. It has been noted that calix[4] pyrrole-based compounds can be considered one of the promising scaffolds for developing anti-cancerous compounds. This paves an excellent approach to use calix[4]pyrrole derivatives in the field of pharmacology.

\section{Materials and Methods}

All chemicals and solvents were of analytical grade or the highest purity available and were purchased from commercial sources and used without further purification. All aqueous solutions were prepared from Millipore water (resistivity, $18 \mathrm{M} \Omega \mathrm{cm} @ 25^{\circ} \mathrm{C}$; Millipore Systems).

\subsection{Synthesis of calix[4]pyrrole compounds, HMCP and MCPTH.}

Meso-tetra(methyl) meso-tetra(3-methoxy,4-hydroxyphenyl) calix[4]pyrrole, HMCP (scheme S1) was prepared according to previously reported procedure [18] using 4-hydroxy, 3 -methoxy acetophenone $(5.0 \mathrm{gm}, 0.0299 \mathrm{~mol})$ and pyrrole $(0.0299 \mathrm{~mol})$ as starting compounds and $\mathrm{BF}_{3}$. $\left(\mathrm{Et}_{2} \mathrm{O}\right)_{2}$ as acid catalyst. To synthesize $\mathrm{MCPTH}$, the ester derivative of HMCP (5.00 gm, $0.0041 \mathrm{~mol})$ and hydrazine hydrate $(0.0664 \mathrm{~mol})$ was dissolved in freshly distilled methanol: toluene solvent (50:50) and stirred under reflux condition for $12 \mathrm{~h}$. The solvent was removed in a vacuum, and the pale-yellow solid was suspended in dichloromethane $(50 \mathrm{~mL})$. The suspension was filtered and washed with dichloromethane $(3 \times 20 \mathrm{~mL})$. The crude 
compound was recrystallized in hot water to give compound MCPTH with $65 \%$ yield (Characterization in supplementary information).

\subsection{Experimental procedure for SRB assay.}

The cell lines were cultured in RPMI 1640 media with $10 \%$ fetal bovine serum and 2 mM L-glutamine. As reported earlier, [19,20], the cells were inoculated into 96 well microtiter plates in $100 \mu \mathrm{L}$ at plating densities depending on the doubling time of individual cell lines. Subsequently, the microtiter plates were incubated at $37^{\circ} \mathrm{C}, 5 \% \mathrm{CO}_{2}, 95 \%$ air, and $100 \%$ relative humidity for $24 \mathrm{~h}$ before adding experimental drugs. Experimental drugs were initially solubilized in dimethyl sulfoxide at $100 \mathrm{mg} / \mathrm{mL}$, diluted to $1 \mathrm{mg} / \mathrm{ml}$ using water, and stored frozen prior to use. During the drug addition, an aliquot of frozen concentrate $(1 \mathrm{mg} / \mathrm{mL})$ was thawed and diluted to $100 \mu \mathrm{g} / \mathrm{mL}, 200 \mu \mathrm{g} / \mathrm{mL}, 400 \mu \mathrm{g} / \mathrm{mL}$, and $800 \mu \mathrm{g} / \mathrm{mL}$ with a complete medium containing test article. Later, the drug aliquots of $10 \mu \mathrm{L}$ of $10 \mathrm{ml}$ were added to the appropriate microtiter wells already containing $90 \mu \mathrm{L}$ of the medium, resulting in the required final drug concentrations, i.e., $10 \mu \mathrm{g} / \mathrm{mL}, 20 \mu \mathrm{g} / \mathrm{mL}, 40 \mu \mathrm{g} / \mathrm{mL}, 80 \mu \mathrm{g} / \mathrm{mL}$.

\subsection{Computational method.}

Intermolecular interactions between compounds $\mathrm{A}, \mathrm{B}$, and $\mathrm{C}$ with quinone reductase- 2 (PDB: 4zvm) were investigated by Molecular Docking. The oxidized form of quinone reductase 2 structure of Human (PDB:4zvm) at a resolution of $1.97 \AA$ [21,22] was first retrieved by pymol from RCSB database [23]. Doxorubicin site of protein was used as the binding site, and ligands were docked via Lamarckian genetic algorithm (LGA) as implemented in Autodock 4.2 program [24]. Chain A and B of quinone reductase- 2 were taken along with flavin-adenine dinucleotide (FAD), whereas water molecules were removed during protein preparation and input file. Protein was prepared via retaining one chain $A$, and heteroatoms, including water molecules, were removed. Further preparation of the protein was performed by ADTtools, whereby hydrogens were added, and charges were assigned by the Kollman scheme. The system was restrained to a grid box with dimensions of $60 \times 96 \times 106$ $\AA 3$ and a $0.312 \AA$ grid spacing, with $\mathrm{x}, \mathrm{y}, \mathrm{z}$ centering $52.25 * 7.78 * 11.35$ in which almost the entire ligand site was involved. All other parameters were maintained at their default values. CASTp server was used to predict cavity mapping and calculation of surface area and volume of the cavity [25]. FTMap was used to probe the site and residue frequencies to form the hydrophobic and H-bond interactions [26].

\section{Results and Discussion}

\subsection{Cytotoxicity of calix[4]pyrrole derivatives.}

It is well known that supramolecules such as calixarene, cyclodextrins, and most recently, cucurbiturils have been actively used in the field of bio-medicinal chemistry $[27,28]$. Very recently, the anti-cancer efficacy of calixarene compounds has emerged as a subject of interest among biochemists and academic researchers [29,30]. Using calixarenes for biomedical applications has proved to be an excellent choice due to its non-toxic nature, vulnerability to chemical modification, and cost-effectiveness (it requires simple starting compounds). In the present study, basic calix[4]pyrrole, HMCP have shown excellent anticancer activity against HeLa and MCF-7 human cancer cell lines in comparison to its hydrazide 
derivative, meso-tetra (methyl) meso-tetra (3-methoxy 4-hydroxy phenoxy acetatohydrazide) calix[4]pyrrole. It has been reported that the US clinical trials database shows only one Phase I study of OTX008, which is a calixarene-based compound and galectin-1 inhibitor with potential antiangiogenic and antineoplastic activity [31]. However, despite the lack of clinical trial evidence, the present work has postulated the mechanistic insights for the anti-cancer activity.

Fig. 1 and 2 display the anti-cancer activities of HMCP and MCPTH towards HeLa and MCF 7 cell lines using adriamycin as control positive. Since HMCP possesses more hydrogen bond donor functional groups in its structure than MCPTH, the anti-cancer efficacy has shown to be more potent. This is because the halogen acids, $\mathrm{OH}$ groups, and to a lesser extent $\mathrm{NH}$ groups are strong donors [32]. In our case, the ability of an -OH phenolic bond in HMCP is in a way directly linked to its ionic character and so the electronegativity of the oxygen atom. Shukla et al. studied the in vitro anti-cancer activity and docking of Schiff bases of 4-amino1,2-naphthoquinone and concluded that Schiff base with electron-withdrawing substituents on phenyl ring exhibited diminished activity [33]. It is conceived that calixarene-based compounds may act through a distinct mechanism, and further studies are needed to deeply understand their mechanism of action.
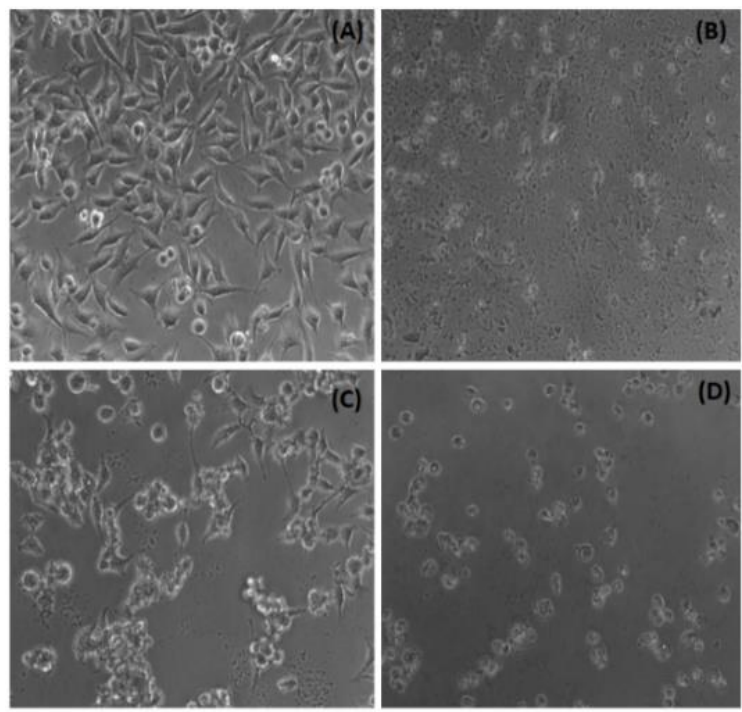

Figure 1. Cytotoxic activity towards HeLa cell lines (a) control (b) HMCP (C) MCPTH (d) positive control (Adriamycin).

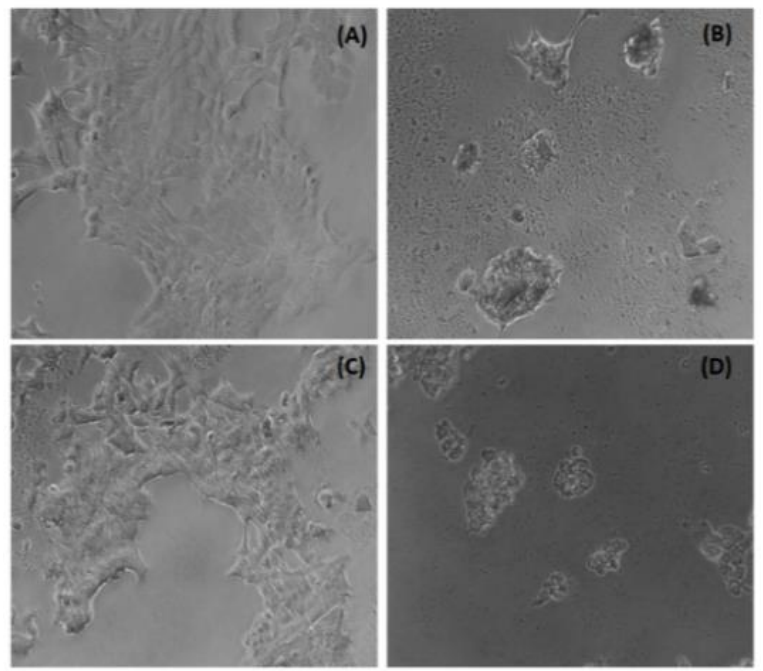

Figure 2. Cytotoxic activity towards MCF-7 cell lines (a) control (b) HMCP (C) MCPTH (d) Positive control (Adriamycin). 


\subsection{Computational insights to understand the cytotoxicity behavior.}

Additional molecular modeling studies could give deeper insights to substantiate the in vitro cytotoxicity results [34-36]. The binding site of quinone reductase- 2 was mapped by the CASTp webserver (Fig. S1), and it has been found that that site comprises surface area (749.705 $\AA^{2}$ ) and volume (709.22 $\AA^{3}$ ). Looking at the reference interaction of the co-crystal ligand (Fig. S1(b)), we found that doxorubicin showed hydrogen bond interactions with Leu 103, Gly 149, Gly 150, Tyr 155 and Glu 193 and one hydrophobic/ $\pi-\pi$ stacking interaction with Tyr 104 residues. The binding site and residue frequencies for the ligand binding were mapped by the FTMap (Fig. S2, S3). According to computational insights, it has been observed that HMCP binds at the doxorubicin site with an affinity of $-7.6 \mathrm{kcal} / \mathrm{mol}$ (Table 1). Due to the larger volume and extended nature of HMCP, the ligand could not fit fully into the pocket; however, it penetrated the pocket through two arms of the calixpyrrole. One of the rings of HMCP forms pi-pi stack with flavin-adenine dinucleotide (FAD), p-hydroxy counterpart forms H-bond with Ala195 and pi-alkyl interactions with His72, Val69, and Ileu194.

From the docking results, we found that HMCP shows van der Waal interactions with A:Gly149, A:Thr151, A:Met154, A:Ser196, A:Arg200, B:Gly68, B:Phe126, B:Ile128, B:Gln122, A:Glu193, B:Asn66, V:Val64, B:Asn61 (Fig. 3). Also, like doxorubicin, HMCP exhibits pi-anion interaction with FAD302. MCPTH showed weaker interaction (affinity, $6.2 \mathrm{kcal} / \mathrm{mol}$ ) as it cannot generate the pose at the doxorubicin site due to extended structure (Fig. 3). Hence, it is proposed that MCPTH is a non-competitive inhibitor of quinone reductase2.

Table 1. Docking scores and major interactions formed by HMCP and MCPTH

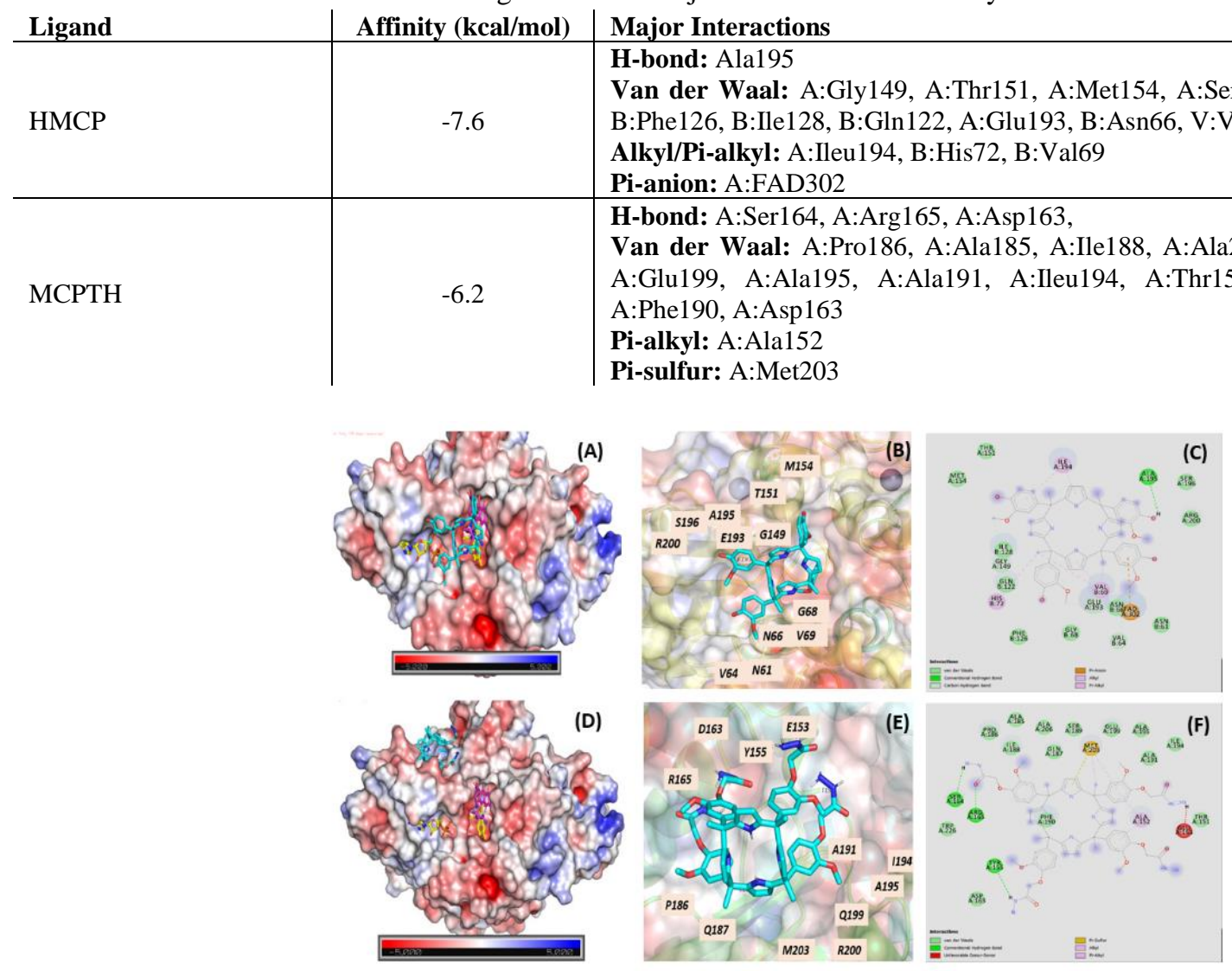

Figure 3. Interaction of ligand with quinone reductase-2. (a,c) Site of Doxorubicin (violet color), Flavin-Adenine dinucleotide (yellow color), and predicted pose for HMCP (cyan color) and MCPTH respectively on the electrostatics surface (ABPS) of the protein; (b,e) predicted poses and (c,f) Protein-ligand interaction map. 


\section{Conclusions}

The anti-cancer activity of calix[4]pyrrole compounds has been studied against HeLa and MCF-7 cancer cell lines, which opens new vistas for biochemists. A new area of calix[4]pyrrole-linked biomedical applications has been explored. Cytotoxicity assays revealed that at concentrations between $10-80 \mu \mathrm{g} / \mathrm{mL}$, the parent $\mathrm{CP}$ molecule was very active with G150 values less than 10 compared to its amine derivative. In support, the present findings provide evidence that HMCP can penetrate the quinone reductase- 2 pocket and thereby provide a rationale to explore as potent anti-cancer therapeutics. Overall, these observations might pave the way for exploring calix[4]pyrrole towards the controlled release of anti-cancer drugs and in targeted chemotherapy.

\section{Funding}

This research received no external funding.

\section{Acknowledgments}

Manoj Vora gratefully acknowledges the financial support received from UGC in the form of the Rajiv Gandhi National Fellowship, RGNF-JRF. The authors also acknowledge UGC Infonet \& Information and Library Network (INFLIBNET) (Ahmedabad) for e-journals. The authors extend their appreciation to the Deanship of Scientific Research at King Khalid University (KKU), Saudi Arabia, for funding through research groups program under grant number R.G.P.2/24/42.

\section{Conflicts of Interest}

The authors declare no conflict of interest.

\section{References}

1. Vora, M.; Dey, S.; Kongor, A.; Panchal, M.K.; Panjwani, F.; Verma, A.; Jain, V.K. An Oxacalix [4] arene derived dual-sensing fluorescent probe for relay recognition of $\mathrm{Hg}^{2+}$ and $\mathrm{S}^{2-}$ ions. New Journal of Chemistry 2021, 45, 17902-17908, https://doi.org/10.1039/D1NJ03953A.

2. Baldini, L.; Casnati, A.; Sansone, F.; Ungaro, R. Calixarene-based multivalent ligands. Chemical Society Reviews 2007, 36, 254-266, https://doi.org/10.1039/B603082N.

3. Pomal, N.C.; Bhatt, K.D.; Modi, K.M.; Desai, A.L.; Patel, N.P.; Kongor, A.; Kolivoška, V. Functionalized Silver Nanoparticles as Colorimetric and Fluorimetric Sensor for Environmentally Toxic Mercury Ions: An Overview. Journal of Fluorescence 2021, 31, 635-649, https://doi.org/10.1007/s10895-021-02699-z.

4. Kumar, B.S.; Chandra, B.; Jovan Jose, K.; Panda, P.K. 1, 2-Phenylene-Incorporated Smallest Expanded Calix [4] pyrrole via One-Step Synthesis of Tetrapyrrane: A Fluorescent Host for Fluoride Ion. The Journal of Organic Chemistry 2021, 86, 10536-10543, https://doi.org/10.1021/acs.joc.1c01179.

5. Basilotta, R.; Mannino, D.; Filippone, A.; Casili, G.; Prestifilippo, A.; Colarossi, L.; Raciti, G.; Esposito, E.; Campolo, M. Role of Calixarene in Chemotherapy Delivery Strategies. Molecules 2021, 26, https://doi.org/10.3390/molecules26133963.

6. Yuksel, N.; Fellah, M.F. Host-guest complex properties of calix [4] arene derivatives: a DFT study of adsorption and sensing of an anti-cancer drug, 5-fluorouracil. Monatshefte für Chemie-Chemical Monthly 2021, 152, 217-228, https://doi.org/10.1007/s00706-021-02736-4.

7. Naseer, M.M.; Ahmed, M.; Hameed, S. Functionalized calix [4] arenes as potential therapeutic agents. Chemical biology \& drug design 2017, 89, 243-256, http://doi.org/10.1111/cbdd.12818.

8. Peng, S.; He, Q.; Vargas-Zúñiga, G.I.; Qin, L.; Hwang, I.; Kim, S.K.; Heo, N.J.; Lee, C.-H.; Dutta, R.; Sessler, J.L. Strapped calix [4] pyrroles: from syntheses to applications. Chemical Society Reviews 2020, 49, 865907, https://doi.org/10.1039/C9CS00528E.

9. Velmurugan, K.; Mohan, M.; Li, B.; Wang, K.; Zuo, M.; Hu, X.-Y. Macrocycles-assisted polymeric selfassemblies fabricated by host-guest complexation and their applications. Materials Advances 2020, 1, 26462662, https://doi.org/10.1039/D0MA00625D. 
10. Kongor, A.; Panchal, M.; Athar, M.; Vora, M.; Verma, N.; Pandya, A.; Jha, P.; Bhadresha, K.; Rawal, R.; Jain, V. Colorimetric and electrochemical sensing of As (III) using calix [4] pyrrole capped gold nanoparticles and evaluation of its cytotoxic activity. Journal of Inclusion Phenomena and Macrocyclic Chemistry 2020, 98, 29-41, https://doi.org/10.1007/s10847-020-01005-x.

11. Kohnke, F.H. Calixpyrroles: From anion ligands to potential anti-cancer drugs. European Journal of Organic Chemistry 2020, 2020, 4261-4272, https://doi.org/10.1002/ejoc.202000208.

12. Lee, J.-S.; Song, I.-h.; Shinde, P.B.; Nimse, S.B. Macrocycles and Supramolecules as Antioxidants: Excellent Scaffolds for Development of Potential Therapeutic Agents. Antioxidants 2020, 9, https://doi.org/10.3390/antiox9090859.

13. Geretto, M.; Ponassi, M.; Casale, M.; Pulliero, A.; Cafeo, G.; Malagreca, F.; Profumo, A.; Balza, E.; Bersimbaev, R.; Kohnke, F.H. A novel calix [4] pyrrole derivative as a potential anti-cancer agent that forms genotoxic adducts with DNA. Scientific reports 2018, 8, 1-16, https://doi.org/10.1038/s41598-018-29314-9.

14. Zhou, J.; Yu, G.; Huang, F. Supramolecular chemotherapy based on host-guest molecular recognition: a novel strategy in the battle against cancer with a bright future. Chemical Society Reviews 2017, 46, 70217053, https://doi.org/10.1039/C6CS00898D

15. Cafeo, G.; Carbotti, G.; Cuzzola, A.; Fabbi, M.; Ferrini, S.; Kohnke, F.H.; Papanikolaou, G.; Plutino, M.R.; Rosano, C.; White, A.J. Drug delivery with a calixpyrrole-trans-Pt (II) complex. Journal of the American Chemical Society 2013, 135, 2544-2551, https://doi.org/10.1021/ja307791j.

16. Kongor, A.; Panchal, M.; Athar, M.; Jha, P.C.; Jhala, D.; Sindhav, G.; Shah, N.; Jain, V.K. Selective fluorescence sensing of $\mathrm{Cu}$ (II) ions using calix [4] pyrrole fabricated Ag nanoparticles: A spectroscopic and computational approach. Journal of Molecular Liquids 2018, 269, 467-475, https://doi.org/10.1016/j.molliq.2018.08.014.

17. Kongor, A.; Panchal, M.; Athar, M.; Makwana, B.; Sindhav, G.; Jha, P.; Jain, V. Synthesis and modeling of calix [4] pyrrole wrapped Au nanoprobe for specific detection of $\mathrm{Pb}$ (II): Antioxidant and radical scavenging efficiencies. Journal of Photochemistry and Photobiology A: Chemistry 2018, 364, 801-810, https://doi.org/10.1016/j.jphotochem.2018.07.024.

18. Kongor, A.; Panchal, M.; Athar, M.; Mehta, V.; Bhatt, K.; Jha, P.; Jain, V. Heterogeneous hydrogenation using stable and reusable calix [4] pyrrole fenced Pt nanoparticles and its mechanistic insight. Applied Surface Science 2018, 437, 195-201, https://doi.org/10.1016/j.apsusc.2017.12.172.

19. Vichai, V.; Kirtikara, K. Sulforhodamine B colorimetric assay for cytotoxicity screening. Nature protocols 2006, 1, 1112-1116, https://doi.org/10.1038/nprot.2006.179.

20. Skehan, P.; Storeng, R.; Scudiero, D.; Monks, A.; McMahon, J.; Vistica, D.; Warren, J.T.; Bokesch, H.; Kenney, S.; Boyd, M.R. New colorimetric cytotoxicity assay for anticancer-drug screening. JNCI: Journal of the National Cancer Institute 1990, 82, 1107-1112, https://doi.org/10.1093/jnci/82.13.1107.

21. Bujacz, A. Structures of bovine, equine and leporine serum albumin. Acta Crystallographica Section D: Biological Crystallography 2012, 68, 1278-1289, https://doi.org/10.1107/S0907444912027047.

22. Boddu, L.; Pagudala, A.K.; Gandamalla, D.; Balabadra, S.; Manga, V.; Yellu, N.R.; Subhashini, N. Synthesis, anti-cancer activity and docking studies of N-phenyl-2-(2-((4-phenyl piperazin-1-yl) methyl)-1H-benzo [d] imidazol-1-yl) acetamides. Journal of Molecular Structure 2018, 1166, 362-368, https://doi.org/10.1016/j.molstruc.2018.04.057.

23. Rose, P.W.; Beran, B.; Bi, C.; Bluhm, W.F.; Dimitropoulos, D.; Goodsell, D.S.; Prlić, A.; Quesada, M.; Quinn, G.B.; Westbrook, J.D. The RCSB Protein Data Bank: redesigned web site and web services. Nucleic acids research 2010, 39, D392-D401, https://doi.org/10.1093/nar/gkq1021.

24. Allouche, A.R. Gabedit-A graphical user interface for computational chemistry softwares. Journal of computational chemistry 2011, 32, 174-182, https://doi.org/10.1002/jcc.21600.

25. Tian, W.; Chen, C.; Lei, X.; Zhao, J.; Liang, J. CASTp 3.0: computed atlas of surface topography of proteins. Nucleic acids research 2018, 46, W363-W367, https://doi.org/10.1093/nar/gky473.

26. Ngan, C.H.; Bohnuud, T.; Mottarella, S.E.; Beglov, D.; Villar, E.A.; Hall, D.R.; Kozakov, D.; Vajda, S. FTMAP: extended protein mapping with user-selected probe molecules. Nucleic acids research 2012, 40, W271-W275, https://doi.org/10.1093/nar/gks441.

27. Lee, J.W.; Samal, S.; Selvapalam, N.; Kim, H.-J.; Kim, K. Cucurbituril homologues and derivatives: new opportunities in supramolecular chemistry. Accounts of chemical research 2003, 36, 621-630, https://doi.org/10.1021/ar020254k.

28. Gidwani, B.; Vyas, A. A comprehensive review on cyclodextrin-based carriers for delivery of chemotherapeutic cytotoxic anti-cancer drugs. BioMed research international 2015, 2015, https://doi.org/10.1155/2015/198268.

29. Li, Y.; Liu, S.; Liang, M.; Cui, Y.; Zhao, H.; Gao, Q. Glycocalixarene with Luminescence for Warburg Effectmediated Tumor Imaging and Targeted Drug Delivery. Chemical Communications 2021, 57, 9728-9731, https://doi.org/10.1039/D1CC04169J.

30. Pan, Y.C.; Hu, X.Y.; Guo, D.S. Biomedical applications of calixarenes: state of the art and perspectives. Angewandte Chemie International Edition 2021, 60, 2768-2794, https://doi.org/10.1002/anie.201916380. 
31. Yousaf, A.; Abd Hamid, S.; Bunnori, N.M.; Ishola, A. Applications of calixarenes in cancer chemotherapy: facts and perspectives. Drug design, development and therapy 2015, 9, 2831-2838, https://doi.org/10.2147/DDDT.S83213.

32. Bellamy, L. Associated XH Frequencies, The Hydrogen Bond. In: The Infrared Spectra of Complex Molecules. Springer: 1980; pp. 240-92, https://doi.org/10.1007/978-94-011-6520-4.

33. Shukla, S.; Srivastava, R.; Shrivastava, S.; Sodhi, A.; Kumar, P. Synthesis, characterization, in vitro anticancer activity, and docking of Schiff bases of 4-amino-1, 2-naphthoquinone. Medicinal Chemistry Research 2013, 22, 1604-1617, https://doi.org/10.1016/j.bjbas.2016.01.001.

34. Fahmy, S.A.; Ponte, F.; Fawzy, I.M.; Sicilia, E.; Bakowsky, U.; Azzazy, H.M.E.-S. Host-Guest Complexation of Oxaliplatin and Para-Sulfonatocalix [n] Arenes for Potential Use in Cancer Therapy. Molecules 2020, 25, https://doi.org/10.3390/molecules25245926.

35. Goudzal, A.; Hadaji, E.; Bouachrine, M.; El Hamdani, H.; Ouammou, A. QSAR and docking molecular models to predict anti-cancer activity on a series of azacalix [2] arene [2] pyrimidine derivatives as anticancer agents. Materials Today: Proceedings 2020, https://doi.org/10.1016/j.matpr.2020.08.002.

36. Moussa, Y.E.; Venkataramanan, N.S.; Wheate, N.J. Demonstration of the first known 1: 2 host-guest encapsulation of a platinum anti-cancer complex within a macrocycle. Journal of Inclusion Phenomena and Macrocyclic Chemistry 2020, 96, 145-154, https://doi.org/10.1007/s10847-019-00960-4. 


\section{Supplementary Information}

\section{Synthesis of HMCP and MCPTH}

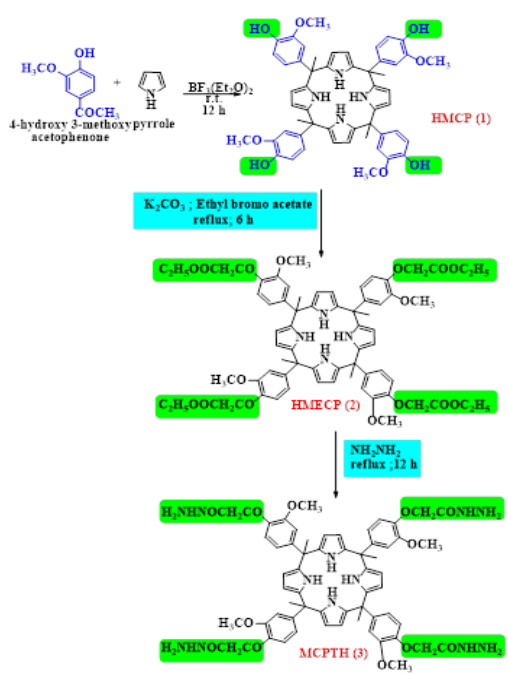

Scheme S1. Synthesis of HMCP and MCPTH [1-2]

Characterization of HMCP: ${ }^{1} \mathrm{H}$ NMR (400 MHz, DMSO): $\delta=1.78\left(12 \mathrm{H}, \mathrm{s}, \mathrm{CH}_{3}\right), 3.65$ $\left(12 \mathrm{H}, \mathrm{m}, \mathrm{OCH}_{3}\right), 5.59-5.89$ (8 H, d, pyrr.CH), 6.57 (12 H, m, ArH), 8.74 (4 H, s, OH), 9.66(4 $\mathrm{H}, \mathrm{s},-\mathrm{NH}) ;{ }^{13} \mathrm{C}$ NMR (100 MHz, DMSO): $\delta=147.47,145.3,141.04,137.22,119.04,114.69$, 112.31, 104.54, 55.95, 43.64, 31.62; ESI-MS m/z: $861.8[\mathrm{M}+\mathrm{H}]^{+}$; M.P. $185^{\circ} \mathrm{C}$

Characterization of MCPTH: ${ }^{1} \mathrm{H}$ NMR (400 MHz, DMSO): $\delta=1.79\left(12 \mathrm{H}, \mathrm{s}, \mathrm{CH}_{3}\right)$, 3.61-3.71 (12 H, $\left.\mathrm{OCH}_{3}\right), 4.42\left(8 \mathrm{H}, \mathrm{d}, \mathrm{NH}_{2}\right), 4.45\left(8 \mathrm{H}, \mathrm{s}, \mathrm{OCH}_{2}\right), 5.80(8 \mathrm{H}$, s, pyrr. $\mathrm{CH}), 6.69$ $(12 \mathrm{H}, \mathrm{d}, \mathrm{ArH}), 9.15(4 \mathrm{H}, \mathrm{s}, \mathrm{NH}), 9.66(4 \mathrm{H}, \mathrm{s}, \mathrm{CONH}) ;{ }^{13} \mathrm{C} \mathrm{NMR}(100 \mathrm{MHz}, \mathrm{DMSO}) \delta=$ 166.86, 148. 66, 137.37, 112.52, 105.07, 67.48, 55.06, 44.14, 31.43; ${ }^{13} \mathrm{C}$ DEPT $(100 \mathrm{MHz}$, DMSO) $\delta=67.50$; ESI-MS: $1171.4[\mathrm{M}+\mathrm{Na}]^{+}$; M.P. $164^{\circ} \mathrm{C}$.

\section{Endpoint measurement.}

After compound addition, plates were incubated at standard conditions for 48 hours, and the assay was terminated by the addition of cold TCA. Cells were fixed in situ by the gentle addition of $50 \mu \mathrm{l}$ of cold $30 \%$ (w/v) TCA (final concentration, $10 \%$ TCA) and incubated for 60 minutes at $4{ }^{\circ} \mathrm{C}$. The supernatant was discarded; the plates were washed five times with tap water and air-dried. Sulforhodamine B (SRB) solution $(50 \mu \mathrm{l})$ at $0.4 \%(\mathrm{w} / \mathrm{v})$ in $1 \%$ acetic acid was added to each of the wells, and plates were incubated for 20 minutes at room temperature. After staining, the unbound dye was recovered, and the residual dye was removed by washing five times with $1 \%$ acetic acid. The plates were air-dried. The bound stain was subsequently eluted with $10 \mathrm{mM}$ trizma base, and the absorbance was read on a plate reader at a wavelength of $540 \mathrm{~nm}$ with $690 \mathrm{~nm}$ reference wavelength. Percent growth was calculated on a plate-byplate basis for test wells relative to control wells. Percent Growth was expressed as the ratio of average absorbance of the test well to the average absorbance of the control wells $* 100$.

Using the six absorbance measurements [time zero (Tz), control growth (C), and test growth in the presence of drug at the four concentration levels (Ti)], the percentage growth was calculated at each of the drug concentrations levels. Percentage growth inhibition was calculated as:

$$
[\mathrm{Ti} / \mathrm{C}] \times 100 \%
$$




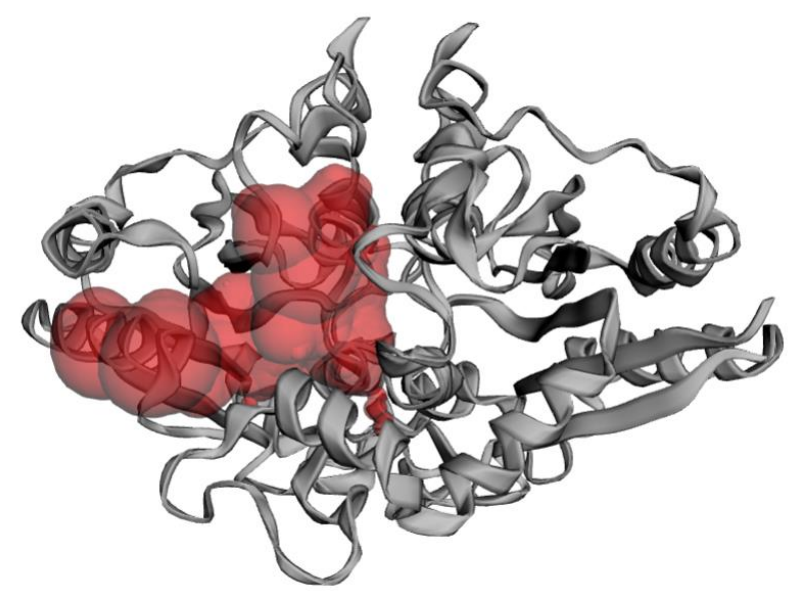

(a)

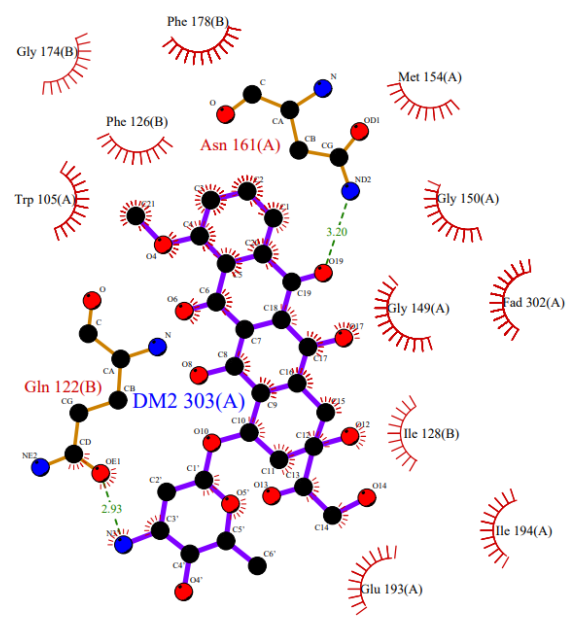

(b)

Figure S1. (a) CASTp doxorubicin site (b)Ligand active site definition used for the generation of grid-box for the docking.

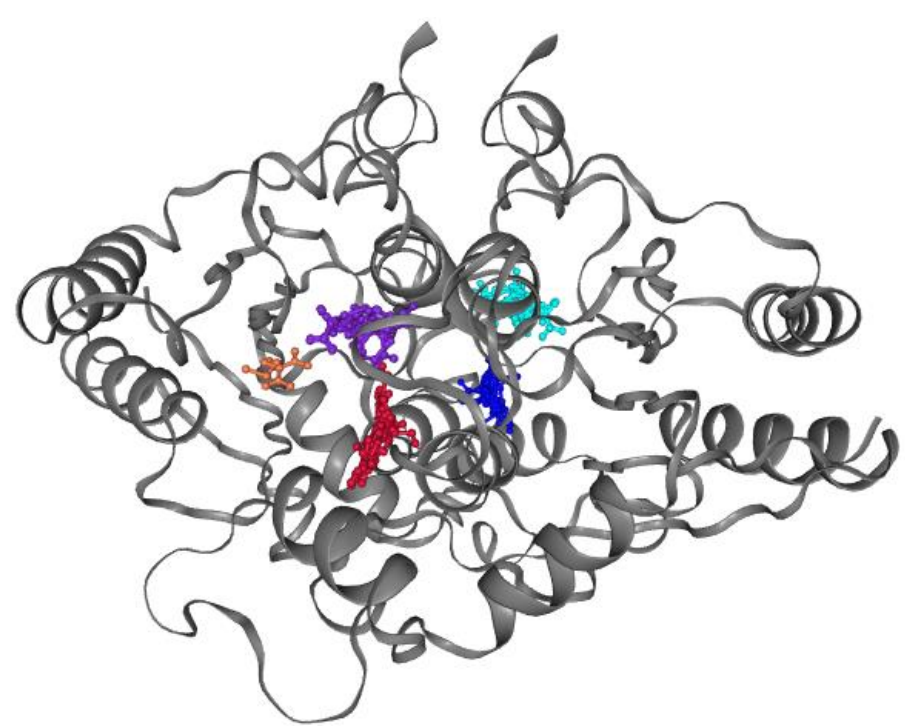

Figure S2. FTmap showing the promising sites and cavities amenable for ligand binding.
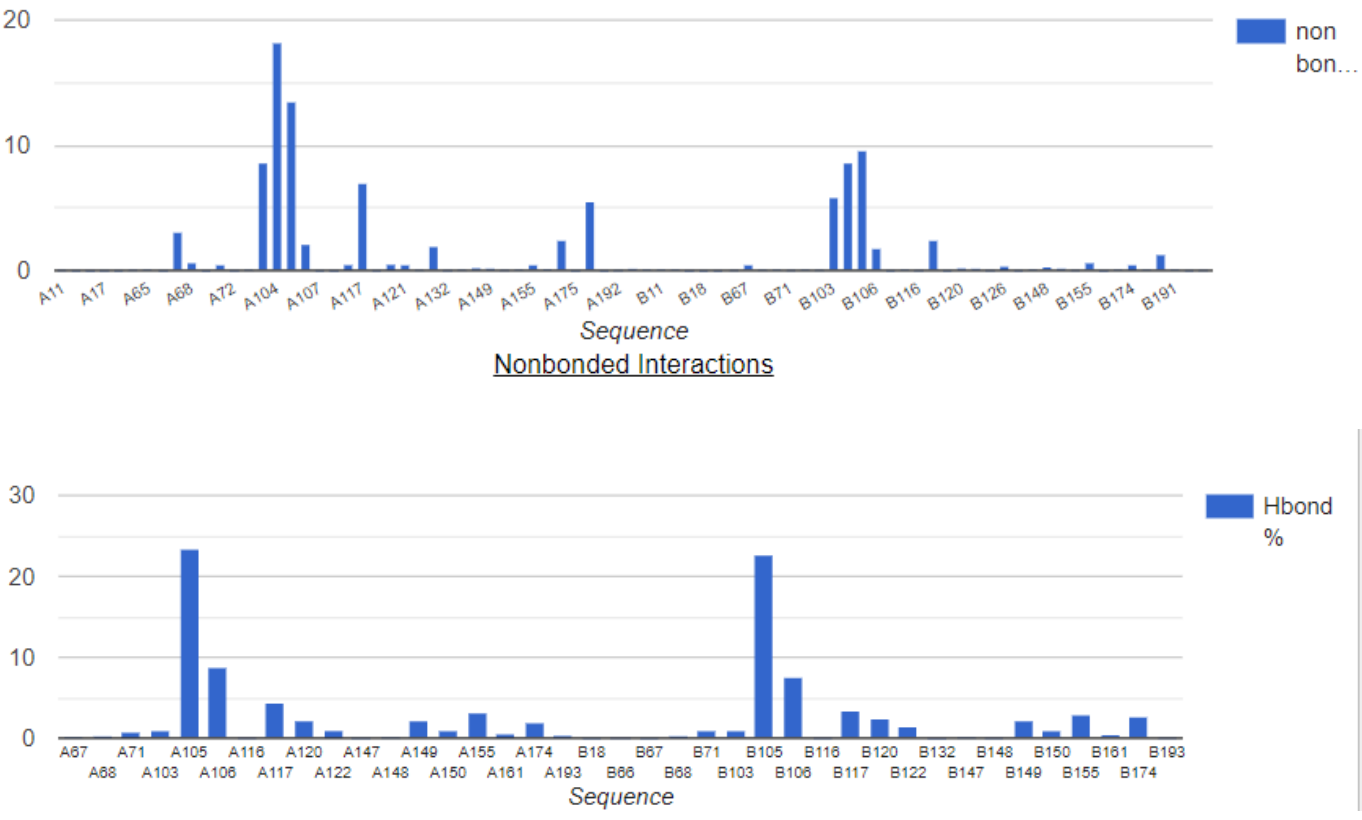

Figure S3. Frequency of the residue contributing to the ligand binding. 